\title{
ANALYSIS OF STUDENTS' SOMATIC HEALTH AND EMOTIONAL STATE DURING SPORTS GAMES CLASSES
}

DOI: $10.36740 /$ WLek202103208

\author{
Iryna I. Shaposhnikova', Svitlana M. Korsun' , Larysa P. Arefieva², Olga V. Kostikova ${ }^{3}$, Volodymyr M. Serhiienko ${ }^{4}$, \\ Svitlana A. Korol ${ }^{4}$, Viktor G. Riabchenko ${ }^{5}$ \\ 'KHARKIV STATE ACADEMY OF PHYSICAL CULTURE, KHARKIV, UKRAINE \\ 2NATIONAL PEDAGOGICAL DRAGOMANOV UNIVERSITY, KYIV, UKRAINE \\ ${ }^{3}$ H.S. SKOVORODA KHARKIV NATIONAL PEDAGOGICAL UNIVERSITY, KHARKIV, UKRAINE \\ "SUMY STATE UNIVERSITY, SUMY, UKRAINE \\ ${ }^{5}$ ACADEMY OF THE STATE PENITENTIARY SERVICE, CHERNIHIV, UKRAINE
}

\begin{abstract}
The aim: Is to investigate the impact of sports games (football) on the level of somatic health and emotional state of students in the process of studying. Materials and methods: The study was conducted at Kharkiv State Academy of Physical Culture and Sumy State University (Ukraine) in 2018-2019. The study involved 87 male students of the main department. Two groups were formed: an experimental group ( $E G, n=42)$, the students of which were engaged in a sports-oriented form of physical education (in the class of football), and a control group ( $(G, n=45)$, the students of which were training according to the traditional methods of organizing physical education classes at higher education institutions. The somatic health of students was assessed according to the method of H. L. Apanasenko, which provided for the determination of body mass, life, power, and Robinson indexes, heart rate recovery time after a standard exercise. The emotional state of students was determined by the WAM (Well-being, Activity, Mood) methodology.

Results: At the end of the study, the EG students showed a significantly better level of somatic health than the CG students; the difference was significant and accounted for 3.18 points $(p<0.001)$. At the same time, during the study, the $E G$ students had a more pronounced significant increase in all studied health indicators ( $p<0.001)$. The best emotional state level of the students of both groups was recorded at the end of the study, but in the EG students it was significantly ( $p<0.05)$ better than in the $C G$ students by $0.55-0.73$ points.

Conclusions: It was found that sports games classes, including football, had a positive effect on the level of somatic health and emotional state of students. Significant changes were observed in the performance of the respiratory and cardiovascular systems of students. The high level of somatic health and good emotional state of students will help to improve mastering academic disciplines at higher education institutions, provide preparation for active life and help to improve future professional activities.
\end{abstract}

KEY WORDS: somatic health, students, football

Wiad Lek. 2021;74(3 p.II):608-612

\section{INTRODUCTION}

It is known that the current state of health and physical fitness of university students of Ukraine is unsatisfactory $[1,2,3]$. The works of many scientists $[4,5,6]$ mention that the "biological" age of most students outruns the passport age by $10-15$ years; from $50 \%$ to $90 \%$ of students (according to various authors) have health disorders; the health of most students is not improved during their studies at higher education institutions (HEI), but, on the contrary, it deteriorates; the number of students with low and below the middle levels of somatic health ranges from $60 \%$ to $85 \%$ at different HEI and is constantly increasing, according to various researchers. The scientists [7-11] consider this situation to be a consequence of the inefficient functioning of the existing system of physical education at educational institutions (schools, higher education institutions).

According to many scientists [12-15], one of the ways to improve the health of students while they are studying at HEI is the introduction of a sports-oriented form of physical education - physical education with a sports focus, which takes into account students' choice of sports they would like to do during physical education classes.

One of the effective means of physical education, which can positively affect the health level of students and improve their emotional state is sports games, among which the most honorable place is occupied by football [16]. Football is quite a common sport in many countries around the world. In addition, according to scientists [17], nowadays football is one of the most effective mechanisms for mass involvement of young people in exercises and sports, the increase of their physical activity, which helps to strengthen their health and motivation to engage in physical education and sports. Football is a well-known game, especially attractive for boys, which plays a great educational role in developing 
Table I. Dynamics of somatic health indicators of $E G$ and $(G$ students in the process of studying at higher education institutions $(n=87)$

\begin{tabular}{|c|c|c|c|}
\hline \multirow{2}{*}{$\begin{array}{l}\text { Terms } \\
\text { of study }\end{array}$} & \multirow{2}{*}{$\begin{array}{c}E G(n=42) \\
X \pm m\end{array}$} & CG $(n=45)$ & \multirow{2}{*}{$\begin{array}{c}\text { Significance } \\
\text { level }\end{array}$} \\
\hline & & $X \pm m$ & \\
\hline \multicolumn{4}{|c|}{$\mathrm{BMI}, \mathrm{kg} / \mathrm{m}^{2}$} \\
\hline $1 \mathrm{st}$ & $22.73 \pm 0.52$ & $22.75 \pm 0.48$ & $p>0.05$ \\
\hline 2nd & $22.77 \pm 0.50$ & $23.08 \pm 0.46$ & $p>0.05$ \\
\hline $3 r d$ & $22.78 \pm 0.48$ & $23.51 \pm 0.47$ & $p>0.05$ \\
\hline 4th & $22.76 \pm 0.47$ & $23.92 \pm 0.50$ & $p>0.05$ \\
\hline \multicolumn{4}{|c|}{$\mathrm{LI}, \mathrm{ml} / \mathrm{kg}$} \\
\hline $1 \mathrm{st}$ & $57.28 \pm 0.61$ & $57.31 \pm 0.65$ & $p>0.05$ \\
\hline 2nd & $58.62 \pm 0.60$ & $57.14 \pm 0.62$ & $p>0.05$ \\
\hline $3 r d$ & $59.97 \pm 0.59$ & $57.02 \pm 0.60$ & $p<0.01$ \\
\hline 4th & $61.03 \pm 0.62$ & $56.91 \pm 0.61$ & $\mathrm{p}<0.001$ \\
\hline \multicolumn{4}{|c|}{$\mathrm{Pl}, \%$} \\
\hline $1 \mathrm{st}$ & $58.85 \pm 0.62$ & $58.90 \pm 0.65$ & $p>0.05$ \\
\hline 2nd & $59.07 \pm 0.65$ & $59.05 \pm 0.67$ & $p>0.05$ \\
\hline $3 r d$ & $59.92 \pm 0.66$ & $59.24 \pm 0.69$ & $p>0.05$ \\
\hline 4th & $60.67 \pm 0.68$ & $59.31 \pm 0.71$ & $p>0.05$ \\
\hline \multicolumn{4}{|c|}{ Rl, c. u. } \\
\hline $1 \mathrm{st}$ & $86.29 \pm 0.71$ & $86.32 \pm 0.64$ & $p>0.05$ \\
\hline 2nd & $85.70 \pm 0.65$ & $85.94 \pm 0.62$ & $p>0.05$ \\
\hline $3 r d$ & $83.92 \pm 0.62$ & $85.11 \pm 0.59$ & $p>0.05$ \\
\hline 4th & $81.83 \pm 0.58$ & $84.79 \pm 0.57$ & $p<0.01$ \\
\hline \multicolumn{4}{|c|}{ Heart rate recovery time, $\mathrm{s}$} \\
\hline $1 \mathrm{st}$ & $128.4 \pm 2.21$ & $129.0 \pm 2.32$ & $p>0.05$ \\
\hline 2nd & $122.1 \pm 2.15$ & $125.8 \pm 2.27$ & $p>0.05$ \\
\hline $3 \mathrm{rd}$ & $115.5 \pm 2.10$ & $121.4 \pm 2.22$ & $p>0.05$ \\
\hline 4th & $106.7 \pm 2.07$ & $117.5 \pm 2.15$ & $p<0.01$ \\
\hline \multicolumn{4}{|c|}{ Somatic health level, points } \\
\hline $1 \mathrm{st}$ & $2.08 \pm 0.25$ & $2.11 \pm 0.21$ & $p>0.05$ \\
\hline 2nd & $3.14 \pm 0.23$ & $2.89 \pm 0.22$ & $p>0.05$ \\
\hline $3 r d$ & $5.87 \pm 0.20$ & $3.51 \pm 0.22$ & $\mathrm{p}<0.001$ \\
\hline 4th & $7.20 \pm 0.19$ & $4.02 \pm 0.23$ & $\mathrm{p}<0.001$ \\
\hline
\end{tabular}

team play skills [18]. Regular football activities contribute to a significant increase in endurance, speed, and power, improve coordination and have a positive effect on all the systems and organs of the body by increasing the amount of oxygen consumed (which is especially important for the heart) [19]. In addition, playing football strengthens the bones, which significantly reduces the risk of fractures when falling [20]. Systematic sports games (football) help to improve the vital capacity of the lungs and maximum oxygen consumption in comparison with untrained individuals. Besides, playing football leads to the formation of a more economical version of the cardiovascular system functioning at rest [18]. According to scientists [16, 20], all sports games are associated with psychological loads different in nature and intensity, and football is no exception.

\section{THE AIM}

The aim of this study is to investigate the impact of sports games (football) on the level of somatic health and emotional state of students in the process of studying.

\section{MATERIALS AND METHODS}

The study was conducted at Kharkiv State Academy of Physical Culture and Sumy State University (Ukraine) in 2018-2019. The study involved 87 male students of the main department. Two groups were formed: an experimental group (EG, $n=42$ ), the students of which were engaged in a sports-oriented form of physical education (in the class of football), and a control group (CG, $n=45$ ), the students of which were training according to the traditional methods of organizing physical education classes at HEI. The number of hours for physical education was the same in both groups.

The somatic health of students was assessed according to the method of H. L. Apanasenko, which provided for the determination of body mass, life, power, and Robinson indexes, heart rate recovery time after a standard exercise. The emotional state of students was determined by the WAM (Well-being, Activity, Mood) methodology.

The research methods: theoretical (analysis, synthesis, and generalization of educational, scientific, and methodical literature, comparison); empirical (pedagogical observation, pedagogical testing, pedagogical experiment); statistical analysis.

The research was performed according to the requirements of the Regulations on Academic Honesty of Kharkiv State Academy of Physical Culture and Sumy State University, which were developed on the basis of Ukrainian and world experience of ethical rulemaking. The consent was obtained from participants in the scientific process and respondents who could refuse to participate in it at any time.

\section{RESULTS}

The analysis of body mass index (BMI) showed that in all terms of study, except for the 1st one, BMI was better in the EG in comparison with the CG, but no significant difference between them was recorded ( $p>0.05)$. BMI of students of both groups in all terms was within the norm for males $\left(18.50-24.99 \mathrm{~kg} / \mathrm{m}^{2}\right)$. The difference between the BMI in the 1st and 4th terms in the EG accounted for $0.03 \mathrm{~kg} / \mathrm{m}^{2}$ and was insignificant ( $p>0.05$ ). In the CG, the indicators of the 4 th term were worse than those of the 1st one by $1.17 \mathrm{~kg} / \mathrm{m}^{2}(\mathrm{p}>0.05)$ (Table I).

The study of the Life index (LI) shows that no significant difference between the indicators of the EG and CG students was found in the 1 st and 2 nd terms ( $p>0.05)$. The LI of EG students was significantly better than that of CG students by $2.95 \mathrm{ml} / \mathrm{kg}$ in the $3 \mathrm{rd}$ term $(\mathrm{p}<0.01)$, and by $4.12 \mathrm{ml} / \mathrm{kg}$ in the 4 th term $(\mathrm{p}<0.001)$ (Table I). The analysis of the LI dynamics during the experiment showed that the indicators significantly improved by $3.75 \mathrm{ml} / \mathrm{kg}$ in the EG $(\mathrm{p}<0.001)$, and, on the contrary, deteriorated by $0.4 \mathrm{ml} / \mathrm{kg}$ in the CG $(\mathrm{p}>0.05)$. 
Table II. Dynamics of emotional state indicators of EG and $(G$ students in the process of studying at higher education institutions $(n=87)$

\begin{tabular}{cccc}
\hline \multirow{2}{*}{$\begin{array}{c}\text { Terms } \\
\text { of study }\end{array}$} & EG (n=42) & CG (n=45) & \multirow{2}{*}{$\begin{array}{c}\text { Significance } \\
\text { level }\end{array}$} \\
\cline { 2 - 3 } & \multicolumn{4}{c}{ Well-being, points } \\
\hline 1st & $6.95 \pm 0.17$ & $7.01 \pm 0.19$ & $\mathrm{p}>0.05$ \\
\hline 2nd & $7.41 \pm 0.16$ & $7.25 \pm 0.18$ & $\mathrm{p}>0.05$ \\
\hline 3rd & $7.88 \pm 0.14$ & $7.48 \pm 0.16$ \\
\hline 4th & $8.17 \pm 0.12$ & $7.62 \pm 0.17$ & $\mathrm{p}>0.05$ \\
\hline \multicolumn{5}{c}{ Activity, points } \\
\hline 1st & $6.80 \pm 0.21$ & $6.85 \pm 0.18$ & $\mathrm{p}<0.05$ \\
\hline 2nd & $7.29 \pm 0.20$ & $6.99 \pm 0.21$ & $\mathrm{p}>0.05$ \\
\hline 3rd & $7.68 \pm 0.21$ & $7.24 \pm 0.20$ & $\mathrm{p}>0.05$ \\
\hline 4th & $8.08 \pm 0.20$ & $7.46 \pm 0.22$ & $\mathrm{p}>0.05$ \\
\hline \multicolumn{5}{c}{ Mood, points } \\
\hline 1st & $6.47 \pm 0.19$ & $6.60 \pm 0.17$ & $\mathrm{p}<0.05$ \\
\hline 2nd & $6.95 \pm 0.18$ & $7.01 \pm 0.21$ & $\mathrm{p}>0.05$ \\
\hline 3rd & $7.26 \pm 0.18$ & $7.19 \pm 0.20$ & $\mathrm{p}>0.05$ \\
\hline 4th & $7.98 \pm 0.17$ & $7.25 \pm 0.19$ & $\mathrm{p}>0.05$ \\
\hline
\end{tabular}

The Power index (PI) study showed that PI of the EG students was better by $1.36 \%$ in the 4 th term (Table I). During the experiment, the PI in both groups of students was improved (by $1.82 \%$ in the EG and by $0.41 \%$ in CG).

The analysis of the Robinson index (RI) showed that no significant difference between the EG and CG was found in the 1 st -3 rd terms $(p>0.05)$. In the 4 th term, the RI of EG students was significantly better than that of the CG students by 2.96 c.u. $(\mathrm{p}<0.01)$ (Table I). The analysis of the RI dynamics showed a positive trend in both study groups, but the indicators were improved significantly by $4.46 \mathrm{c}$. $u$. in the EG $(\mathrm{p}<0.001)$, and by 1.53 c.u. in the CG insignificantly ( $\mathrm{p}>0.05)$.

The analysis of the heart rate recovery time after 20 squats in $30 \mathrm{~s}$ showed that in the 4th term, the indicators of the EG students was found to be significantly $(\mathrm{p}<0.01)$ better than that of the CG students by $10.8 \mathrm{~s}$ (Table I). The analysis of the somatic health level showed that the indicators of the EG and CG students did not differ significantly in the 1st and 2nd terms ( $p>0.05)$. The somatic health level of the EG students was significantly better than that of the CG students by 2.36 points in the 3 rd term $(\mathrm{p}<0.001)$, and by 3.18 points in the 4 th term $(p<0.001)$ (Table I). The dynamics of the health level of the students of both groups was positive - the results of students in the 4th term were significantly better than in the 1 st $(\mathrm{p}<0.001)$ by 5.12 points in the EG and 1.91 points in the CG. This confirmed the positive impact of football classes on the level of students' somatic health.

The analysis of the emotional state indicators of students according to the WAM methodology showed that a significant difference between the EG and CG was not found in the 1 st -3 rd terms in terms of any studied characteristics (well-being, activity, mood) ( $p>0.05)$ (Table II).
In the 4th term, the indicators of well-being in the EG were significantly $(\mathrm{p}<0.05)$ better than in the CG by 0.55 points, activity indicators - by 0.62 points, mood - by 0.73 points. The analysis of the dynamics of the emotional state of students showed that the indicators were significantly improved in both groups, but the reliability of the difference between the indicators of the 4 th and 1 st terms was $p<0.001$ in the EG, and $\mathrm{p}<0.05$ in the CG. This made it possible to state the positive impact of football classes on the emotional state of students in the process of studying at HEI.

\section{DISCUSSION}

Physical education associated with the process of educating, acquiring the appropriate knowledge and skills to use physical activity for comprehensive development, health-improvement, and readiness for professional activities, and active participation in the life of society $[2,8$, $10]$. The scientists $[13,15]$ argue that physical education at HEI should be a solid foundation for a high level of mental capacity of students in the learning process, involving them in regular exercises, creating the need for physical development and improvement to ensure the health and professional longevity.

The works of many scientists $[3,5,9]$ have established a close relationship between the health, physical fitness of students, and the organization of physical education at HEI. The scientists $[1,4,7]$ note that the existing system of physical education at Ukrainian HEI is not effective enough to improve the somatic health of students during their studies. The scientists $[14,15]$ distinguish the main shortcomings of the existing system of physical education at the Ukrainian HEI: a low level of somatic health and physical fitness of school graduates and, accordingly, HEI applicants; a decrease in the students' interest and motivation for the traditional physical education classes; a decrease in the prestige of health as the most important human value; insufficient health and training orientation of the forms and means of physical education; the lack of differentiated approach in the process of physical education, insufficient variety of the forms of physical education classes organization, etc.

The scientists $[4,8,9]$ note that one of the ways to solve this problem is the introduction of physical education classes with a sports focus. Football is an effective way to promote good somatic health, fitness, and emotional well-being $[17,19]$. Football is a sport that contributes to the most diverse physical development of a person and at the same time places extremely high demands on the organism. Playing football is associated with the need to maintain the high performance for a long time and perform work of maximum intensity against the background of significant general fatigue and stress. Football training produces the ability to master motor actions and restructure motor activity quickly in accordance with the changing environment. Football requires dexterity in movements with the ball, without the ball, in constantly changing game situations $[18,20]$. 
Modern football has diverse and complex techniques. Systematic football classes, participation in competitions in this sport have a comprehensive impact on students: normal physical development is ensured, the functional activity of their body is improved. Playing sports also contributes to the development of some positive traits and qualities of character: the ability to subordinate personal interests to the interests of the team, mutual assistance, respect for rivals and partners, activity, conscious discipline, punctuality, sports ethics, responsibility. Thus, the results of our research confirm the conclusions of many scientists about the positive impact of football on the health and emotional state of students while studying at HEI.

\section{CONCLUSIONS}

It was determined that the level of somatic health was significantly $(\mathrm{p}<0.001)$ better in the EG students than in the CG students at the end of the study, the difference accounted for 3.18 points. The analysis of the somatic health dynamics during the study at HEI showed that there was a more pronounced significant increase in the level of somatic health in the EG $(p<0.001)$. The best emotional state indicators of the students of both groups were recorded at the end of the study, but they were significantly better in the EG than in the CG by 0.55 points in terms of well-being, 0.62 points concerning activity, and 0.73 points $-\operatorname{mood}$ $(\mathrm{p}<0.05)$.

It was found that football classes had a positive effect on the level of somatic health and emotional state of students in the process of physical education at HEI. Significant changes were observed in the indicators of the respiratory and cardiovascular systems of students (in the indicators of LI, RI, heart rate recovery, and somatic health). The high level of health and good emotional state of students will help to improve mastering academic disciplines in the educational process at HEI, provide preparation for active life and help to improve future professional activities.

\section{REFERENCES}

1. Gruzieva T., Galiienko L., Pelo I. et al. Health and lifestyle of students' youth: status, problems and ways of solution. Wiad Lek. 2018; 71(9): 1753-1758.

2. Mozolev 0., Khmara M., Shorobura I. et al. Comparative analysis of the effectiveness of Polish and Ukrainian basic training programs in physical education for 9-10-year-old pupils. Universal Journal of Educational Research. 2019; 7(11): 2345-2351. doi: 10.13189/ujer.2019.071112.

3. Prontenko K., Griban G., Dovgan N. et al. Students' health and its interrelation with physical fitness level. Sport Mont. 2019; 17(3): 41-46. doi 10.26773/smj.191018.

4. Griban G., Lyakhova N., Tymoshenko 0. Current state of students' health and its improvement in the process of physical education. Wiad. Lek. 2020; 73(7), 1438-1447. doi: 10.36740/WLek202007124.

5. Prysiazhniuk S., Tolubko V., Oleniev D. et al. The influence of physical activities on biological age parameters of the first-year female students from the special medical department. Journal of Physical Education and Sport. 2018; 18(2): 561-564. doi:10.7752/jpes.2018.02081.
6. Griban G., Prontenko K., Zhamardiy V. et al. Professional stages of a physical education teacher as determined using fitness technologies. Journal of Physical Education and Sport. 2018; 18(2): 565-569. doi:10.7752/jpes.2018.02082.

7. Mozolev 0. , Bloshchynsky I., Alieksieiev 0 . et al. Influence of modern fitness technologies on the state of health and development of motor abilities of 17-19-year-old female students. Journal of Physical Education and Sport. 2019; 19(3): 917-924. doi:10.7752/jpes.2019. s3132.

8. Prontenko K., Griban G., Aloshyna A. et al. The physical development and functional state as the important components of the students' health. Wiad. Lek. 2019; 72(12a): 2348-2353. doi: 10.36740/WLek201912115.

9. Griban G., Kobernyk 0., Terentieva N. et al. Formation of health and fitness competencies of students in the process of physical education. Sport Mont. 2020; 18(3): 73-78. doi: 10.26773/smj.201008.

10. Zhamardiy V., Shkola 0., Okhrimenko I. et al. Checking of the methodical system efficiency of fitness technologies application in students' physical education. Wiad Lek. 2020; 73 (2): 332-341. doi: 10.36740/ WLek202002125.

11. Griban G., Yavorska T., Tkachenko P. et al. Motor activity as the basis of a healthy lifestyle of student youth. Wiad. Lek. 2020; 73(6): 1199-1206. doi: 10.36740/WLek202006123.

12. Prontenko K., Bloshchynskyi I., Griban G. et al. Formation of readiness of future physical culture teachers for professional activity. Universal Journal of Educational Research. 2019; 7(9): 1860-1868. doi: 10.13189/ ujer.2019.070903.

13. Griban G., Tymoshenko 0., Arefiev V. et al. The role of physical education in improving the health status of students of special medical groups. Wiad. Lek. 2020; 73 (3): 534-540. doi: 10.36740/ WLek202003125.

14. Prontenko K., Griban G., Bloshchynskyi I. et al. Improvement of students' morpho-functional development and health in the process of sport-oriented physical education. Wiad Lek. 2020; 73(1): 161-168. doi: 10.36740/WLek202001131.

15. Mozolev 0., Bloshchynskyi I., Prontenko K. et al. Influence of fitness techniques integration on the development of physical qualities and morpho-functional state of adult females. Human Movement. 2021; 22(1): 57-65. https://doi.org/10.5114/hm.2021.98465.

16. Rago V., Pizzuto F., Raiola G. Relationship between intermittent endurance capacity and match performance according to the playing position in sub-19 professional male football players: Preliminary results. Journal of Physical Education and Sport. 2017; 17(2): 688-691.

17. Castellano J., Blanco-Villasenor A., Alvarez D. Contextual variables and time-motion analysis in soccer. International Journal of Sports Medicine. 2011; 32(6): 415-421. doi: 10.1055/s-0031-1271771.

18. Clemente F. M., Wong D. P., Martins F. M. L., Mendes R. S. Acute effects of the number of players and scoring method on physiological, physical, and technical performance in small-sided soccer games. Research in Sports Medicine. 2014; 22(4): 380-397.

19. Da Silva J., Guglielmo L., Bishop D. Relationship between different measures of aerobic fitness and repeated-sprint ability in elite soccer players. The Journal of Strength and Conditioning Research. 2010;24(8): 2115-2121. doi: 10.1519/JSC.0b013e3181e34794.

20. Sampaio J., Lago C., Goncalves B. et al. Effects of pacing, status and unbalance in time motion variables, heart rate and tactical behavior when playing 5-a-side football small-sided games. Journal of Science and Medicine in Sport. 2014; 17(2): 229-233. 
The research work was performed according to theme of the Department of Biological Disciplines of Kharkiv State Academy of Physical Culture «Biological (anatomical and morphological, biochemical and physiological) foundations of the optimization of the athletes' training process in different kind of sport and during physical education classes» (20182022, № state registration 0117U006381).

\section{ORCID and contibutionship:}

Iryna I. Shaposhnikova: 0000-0003-1020-6486 ${ }^{A, E}$

Svitlana M. Korsun: 0000-0002-2272-8786 ${ }^{B, F}$

Larysa P. Arefieva: 0000-0003-4783-3547 ${ }^{B, D}$

Olga V. Kostikova: 0000-0002-0904-948X ${ }^{C, D}$

Volodymyr M. Serhiienko: 0000-0001-5310-4346 ${ }^{E}$

Svitlana A. Korol: 0000-0002-5270-3467 ${ }^{F}$

Viktor G. Riabchenko: 0000-0002-5630-9459 C

\section{Conflict of interest:}

The Authors declare no conflict of interest.

\section{CORRESPONDING AUTHOR}

Iryna I. Shaposhnikova

Kharkiv State Academy of Physical Culture

99 Klochkivska Street, 61058 Kharkiv, Ukraine

tel: +380975234088;

e- mail: physical_education_2020@ukr.net

Received: 12.10 .2020

Accepted: 06.03.2021

A - Work concept and design, B - Data collection and analysis, C - Responsibility for statistical analysis,

$\mathbf{D}$-Writing the article, $\mathbf{E}$-Critical review, $\mathbf{F}$ - Final approval of the article 